\title{
Balò's concentric sclerosis presenting with benign clinical course and multiple sclerosis-like lesions on magnetic resonance images
}

\author{
Yongmei Li, Peng Xie ${ }^{1}$, Xiao Fan, Huamin Tang \\ Departments of Radiology and ${ }^{1}$ Neurology, the First Affiliated Hospital, Chongqing Medical University, Chongqing, China
}

\begin{abstract}
Address for correspondence: Dr. Peng Xie,

Departments of Radiology and Neurology, The First Affiliated Hospital, Chongqing Medical University, Chongqing, China. E-mail: xiepeng58@21cn.com
\end{abstract}

DOI: $10.4103 / 0028-3886.48815$

\begin{abstract}
Abstrat
Balò's concentric sclerosis (BCS) is a rare primary demyelinating disease of central nervous system (CNS) and is considered to be a variant of multiple sclerosis (MS). It is characterized by a severe, rapidly evolving course with CNS lesions consisting of concentric rings of demyelination alternating with myelination in the white matter. We report a patient with BCS from mainland China diagnosed on magnetic resonance imaging (M RI) findings. In addition to two contrast enhanced open ring lesions. MRI also showed multiple small white matter lesions in both the hemispheres. The patient had a good response to corticosteroids and had a benign prognosis during a follow-up period of two years.
\end{abstract}

Key words: Concentric sclerosis, magnetic resonance imaging, multiple sclerosis

\section{Introduction}

Balò first described the histological features, alternating bands of loss and partially preserved myelin, of this clinical enitity, Balo's concentric scleriosis (BCS). Earlier reports suggested lethal outcomes, but magnetic resonance imaging (MRI) has changed this view and long-term survival has been reported with BCS. ${ }^{[1]}$ More recent reports suggest a benign evolution with spontaneous remission. ${ }^{[1-5]}$ Of the less than 80 cases reported in the literature, most involved young male adults. More cases are from the Asian countries, China, India, and Turkey suggesting possible role of genetic and environmental factors. ${ }^{[2-7]}$ We report a patient with BCS from mainland China with MRI follow-up.

\section{Case Report}

A 37-year-old male was admitted with dizziness and numbness and weakness of right side limbs. Neurological examination revealed loss of orientation to time and place, poor calculation ability and memory disturbance. He also had right supranuclear facial paralysis, right hemiparesis and hemisensory loss.

Cerebrospinal fluid (CSF) examination was abnormal: cell count $27 / \mathrm{mm}^{3}$ and protein $54 \mathrm{mg} / \mathrm{dL}$. CSF immunoglobulin $\mathrm{G}$ index was normal and there was no oligoclonal bands. Visual and brainstem auditory evoked potential studies were normal. Brain MRI, $\mathrm{T}_{2}$-weighted and fluid-attenuated inversion recovery (FLAIR) images showed three lamellar concentric mass lesions are in the white matter of left hemisphere, one in the frontal lobe and two in the periventricular area. On contrast-enhanced MRI, two of the lesions had open-ring enhancement. The maximal diameter of the lesions was $4.0 \mathrm{~cm}$. Interestingly, three small multiple sclerosis-like lesions were also seen, two in the right periventricular white matter and the other in the left lateral ventricular triangle-area [Figure 1a-d].

Patient received $1000 \mathrm{mg} / \mathrm{day}$ intravenous methylprednisolone for five consecutive days. He had improvement in his clinical symptoms at one month follow-up. There was no relapse in the symptoms during the next 27 months of follow-up. Follow-up at 
27 months showed mild memory disturbances and a follow-up MRI showed resolution of the ring lesions and small plaques in the previous regions [Figure 1e, Figure 1f], and the three multiple sclerosis-like lesions were stable. No new lesions were seen.

\section{Discussion}

BCS is a rare primary inflammatory demyelinating disease of the central nervous system. Pathologically, it is characterized by a peculiar pattern of alternating rings of myelin preservation or remyelination and myelin loss, consistent with demyelination, involving the cerebral hemispheres, cerebellum, brainstem and spinal cord. Diagnosis can also be established by biopsy. ${ }^{[6]}$ Stadelmann et al., investigated the immunopathology of BCS. ${ }^{[8]}$ Active concentric lesions followed a pattern of demyelination which resembled hypoxia-tissue injury. Recent MRI studies also support this hypothesis. ${ }^{[9]}$ The diagnosis of BCS is based on clinical signs and symptoms, exclusion of other neurological diseases and the characteristic concentric rings lesions seen by MR images.
BCS has characteristic MRI features; hypo-/isointense concentric rings on $\mathrm{T}_{1}$-weighted image; multiple whirlpool hyperintense concentric rings on $\mathrm{T}_{2}{ }^{-}$ weighted image, and open-ring enhancement of the lesions with Gadolinium. Our patient in addition had small multiple sclerosis-like demyelinating plaques. Advanced neuroimaging can provide important in vivo markers of disease progression. ${ }^{[9]}$ Proton spectroscopy may show high choline peak and low a decrease peak of N-acetylaspartate peak, similar to acute MS plaques.

BCS is considered a rare and acute variant of MS. Our case confirms the earlier observation that BCS can have a benign course without relapses ${ }^{[2-4]}$ Shankar et al. reported a clinically silent case of BCS in a patient with an oligodendroglioma. ${ }^{[7]}$ The important differential diagnosis of BCS includes acute disseminated encephalomyelitis. A similar configuration of MRI lesions can be seen occasionally during an exacerbation of MS. However, the typical concentric pattern on MR images as described above is highly suggestive of BCS.
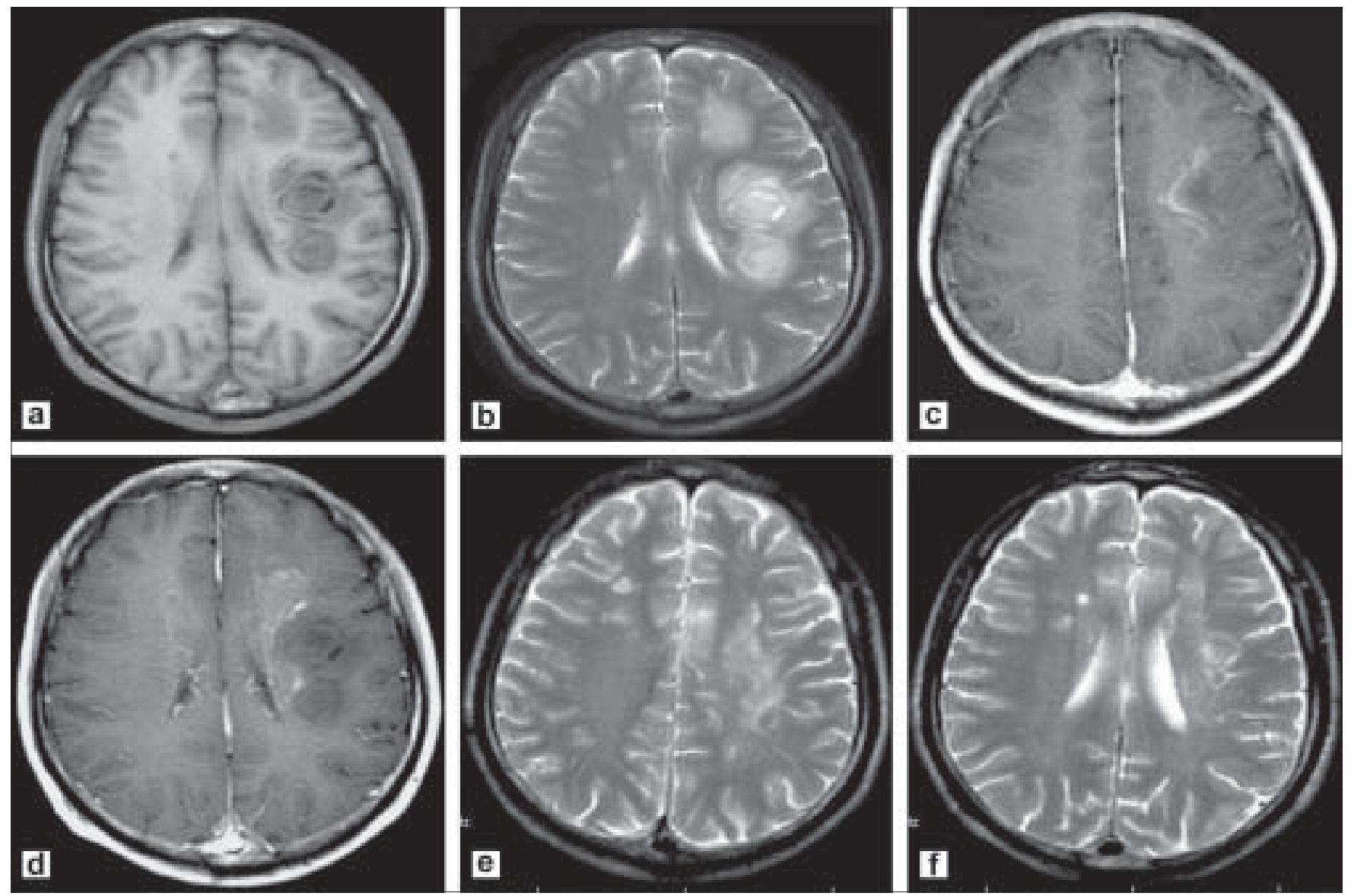

Figure 1: Images in a 37-year-old man (1a) Axial $\mathrm{T}_{1}$-weighted image reveals three hypo-/isointense concentric rings in the supratentorial left cerebral white matter area, two of which were typical concentric images, (1b) Axial $T_{2}$-weighted image displays whirlpool hyperintense concentric rings, two small plaque multiple sclerosis-like lesions were detected in the right frontal white matter, (1c) Axial $\mathrm{T}_{1}$-weighted image after administration of gadolinium-DTPA shows an open-rings enhancement of the lesions, (1d) The next slice of the 1c image shows the patchy enhancement at the edge of the concentric lesions, (1e) and (1f) Axial $T_{2}$-weighted images shows the concentric lesions markedly disappeared after 27 months, and transformed into multiple sclerosis-like small plaques in the previous concentric lesions, the other three multiple sclerosis-like lesions were stable. There was no other new lesion in the brain. 
High dose of steroids may not change the rapidly progressive clinical course of BCS, but most patients have been treated successfully with immunosuppressive drugs. Plasma-exchange and immunosuppressive therapy followed by autologous stem cell transplantation can also be utilized.

\section{References}

1. Lindquist S, Bodammer N, Kaufmann J, Konig F, Heinze HJ, Bruck $\mathrm{W}$, et al. Histopathology and serial, multimodal magnetic resonance imaging in a multiple sclerosis variant. Mult Scler 2007;13:471-82.

2. Gu J, Wang R, Lin J, Fang S. Concentric sclerosis: Imaging diagnosis and clinical analysis of 3 cases. Neurol India 2003;51:528-30.

3. Chaodong W, Zhang KN, Wu XM, Gang H, Xie XF, Qu XH, et al. Balo's disease showing benign clinical course and co-existence with multiple sclerosis-like lesions in Chinese. Mult Scler 2008;14:418-24.

4. Karaarslan E, Altintas A, Senol U, Yeni N, Dincer A, Bayindir C, et al. Baló's concentric sclerosis: clinical and radiologic features of five cases. AJNR Am J Neuroradiol 2001;22:1362-7.

5. Singh S, Kuruvilla A, Alexander M, Korah IP. Balo's concentric sclerosis: Value of magnetic resonance imaging in diagnosis. Australas Radiol 1999;43:400-4.

6. Nandini M, Gourie-Devi M, Shankar SK, Mustare VB, Ravi V. Balo's concentric sclerosis diagnosed intravitam on brain biopsy. Clin Neurol Neurosurg 1993;95:303-9.

7. Shankar SK, Rao TV, Srivastav VK, Narula S, Asha T, Das S. Balo's concentric sclerosis: a variant of multiple sclerosis associated with oligodendroglioma. Neurosurgery 1989;25:982-6.

8. Stadelmann C, Ludwin S, Tabira T, Guseo A, Lucchinetti CF, Leel-OssyL, et al. Tissue preconditioning may explain concentric lesions in Balo type of multiple sclerosis. Brain 2005;128:979-87.

9. Ball T, Malik O, Roncaroli F, Quest RA, Aviv RI. Apparent diffusion coefficient changes and lesion evolution in Balo's type demyelinationd correlation with histopathology. Clin Radiol 2007;62:498-503.

Accepted on 21-01-2009

Source of Support: Nil, Conflict of Interest: None declared.

\section{Staying in touch with the journal}

1) The Table of Contents (TOC) email alert

Receive an email alert containing the TOC when a new complete issue of the journal is made available online. To register for TOC alerts go to w w w.neurologyindia.com/signup.asp.

\section{2) RSS feeds}

Really Simple Syndication (RSS) helps you to get alerts on new publication right on your desktop without going to the journal's website. You need a software (e.g. RSSReader, Feed Demon, FeedReader, My Yahoo!, NewsGator and NewzCrawler) to get advantage of this tool. RSS feeds can also be read through FireFox or Microsoft Outlook 2007. Once any of these small (and mostly free) software is installed, add w w w.neurologyindia.com/rssfeed.asp as one of the feeds. 